\title{
Experience in setting environmental priorities of the regional scheme of strategic planning of Primorsky region
}

\author{
V. N. Bocharnikov ${ }^{1}$, E. G. Egidarev ${ }^{1,2}$, and I. V. Lindberg ${ }^{2}$ \\ ${ }^{1}$ Pacific Geographical Institute FEB RAS, Vladivostok, Russia \\ ${ }^{2}$ World Wildlife Fund (WWF), Amur Branch, Vladivostok, Russia
}

\begin{abstract}
The authors discuss the need for implementing scientific expertise related to the conservation of biodiversity, key ecosystems, and high conservation value areas in order to mitigate the consequences of the anthropogenic impact in the region. In the example of the Primorsky region, the authors considered the possibilities of conducting an effective environmental policy in conditions of the Government's declared commitment to maintaining a favorable investment climate. Based on GIS technologies, environmental zoning is conducted and discussed by authors, anthropogenic changes in geosystems of the Primorsky region are shown, main types of socio-economic systems of the Primorsky region are briefly characterized.
\end{abstract}

\section{The problem statement}

Today's global financial, energy and climate crises highlighted the critical need for searching for new economic growth patterns focused on sustainable development and not the dominant of intensive consumption of an extended range of social services and material goods. The Nature-Society System is a complex multi-level developing system that has specific, hierarchical, structural, and organizational relations. Solving environmental problems should involve scientific developments in all spheres: political (external and internal activities); economic (nature protection expenses accounting; integrated involvement on the regional level); social (improving the quality of life and material well-being); ecological (conservation of biodiversity and resilience of ecosystems) [1-5].

The "dominant" of Geography is the territorial paradigm according to which the territory is considered to be the platform of the interaction of various driving forces and factors, development of society and nature, their territorial conditionality, and intensity. In the process of calculating the percentage of the wildlife locations on a national level, we highlighted "roadless" and "unpopulated" areas, which allowed us to receive comparative estimates for the whole country in binary code (yes-no or "humanized nature"-"wildlife"). As the result, the locations of wildlife areas at the Primorsky region were shown with high accuracy, and the index of wildlife was calculated, it constitutes less than half of the area [67]. Particular attention should be given to the cooperation of scientists with non- 
governmental environmental organizations in order to efficiently integrate informational and research developments in regional environmental activities.

Natural resources are essential for the economic development of Russia, they are a fundamentally important source of income, the geography of human activity is considered to be the driver of changes in the natural state of the environment. It has been repeatedly proven that overexploitation of resources irrevocably changed the environmental sustainability of natural ecosystems which causes the critical loss of biodiversity and reduced quality of ecosystem services on the planet. It should be noted in general that the Primorsky region is crossed from the North to the South by the world's longest Trans-Siberian Railway with its branch railway lines going to the East, to the inner areas, and to the West, to the RussianChinese border. The Primorsky region has strong rail and road connections with all foreign "neighbors". Contact functions of the region are the base for the development of the transport and logistics cluster of the Primorsky region, the significant volume of hydrocarbon materials is planned to be exported through the ports of the Primorsky region. In this regard, the section of the pipeline "Eastern Siberia- Pacific Ocean" goes through the region (the length of oil pipelines is about $550 \mathrm{~km}$ ).

The Primorsky region is a part of the Far Eastern Federal District which area is the largest in Russia (6.2 million sq. $\mathrm{km}$ ) and belongs to the Far Eastern economic macro-region in socio-economic regard. The area of the Primorsky region including big islands under its jurisdiction, i.e. Russky island, Popov Island, Putyatin Island, Askold island, located in the far south-east of Russia, is comparable to the area of several European countries (Bocharnikov and others, 2021). The total area is $165,900 \mathrm{sq} . \mathrm{km}$. The Territory is washed by the Sea of Japan in the south and east, this maritime boundary has great importance, it borders with the forest areas of the Khabarovsk region in the north, it has the border with China in the west which has a length of $1000 \mathrm{~km}$ and connects the Primorsky region with developing northeast regions of China. The only border of the Eurasian country with North Korea is located in the far southwest of the Primorsky region. The advantageous economical and geographical location of the Primorsky region is determined by the fact that its large transboundary area merges with industrialized south regions of the Khabarovsk region and neighboring areas of China in the north, and its south coastline of $1500 \mathrm{~km}$ represents a unique natural area connected to the Pacific Ocean.

The Primorsky region is one of the most valuable areas in terms of environmental protection, it has a rich history of wildlife conservation. The conflict of interest arises, that's why we initiated, developed, and introduced to authorized persons the methodological and informational basis of the scientific expertise of the Government's declared commitment to the development of the investment economy and broad-based attraction of foreign investors, which results are reported in this paper. We came to the conclusion about the critical importance of the need to scientifically evaluate the extent of anthropogenic fracturing and to compare territorial plans of the investment development of the Primorsky region with locations of high conservation value areas, it is reflected in this publication. In order to justify the position regarding nature protection, the authors conducted the situational analysis of spatial information to assess environmental risks of external and internal investing in the economy of the Primorsky region and considered the experience of geo-information support of scientific researches and practical activities on nature protection [8-9].

\section{A brief description of the research object and discussion of the research results}

The authors considered the general schemes for the development of the Primorsky region that were publicly available and came to the conclusion that the schemes were developed by the layer-by-layer method which insufficiently accounts for the environmental component. The 
analysis was conducted on the basis of thematic information layers "Schemes of territorial development of the Primorsky region" (version 2014 updated in 2015) and earlier published materials such as publicly available schemes of development of municipal districts (the agglomeration of Vladivostok, Khasan region, etc). Access to these documents was provided via the Federal Government Information System of Territorial Planning (https://fgistp.economy.gov.ru/). The Primorsky region has good "maritime accessibility" for Japan, Korea, and other countries of the Asia-Pacific region on which basis the special economic cluster "The Free Port of Vladivostok" was organized to ensure transportation of food, fuel, production machines, and equipment to the north-east and east regions of the country through the ice-free ports of the Sea of Japan. The geographical approach of the research allowed us to get a visual understanding of the spatial irregularity of the territory of the region, which became the basis for zoning according to the degree of anthropogenic development (Fig. 1).

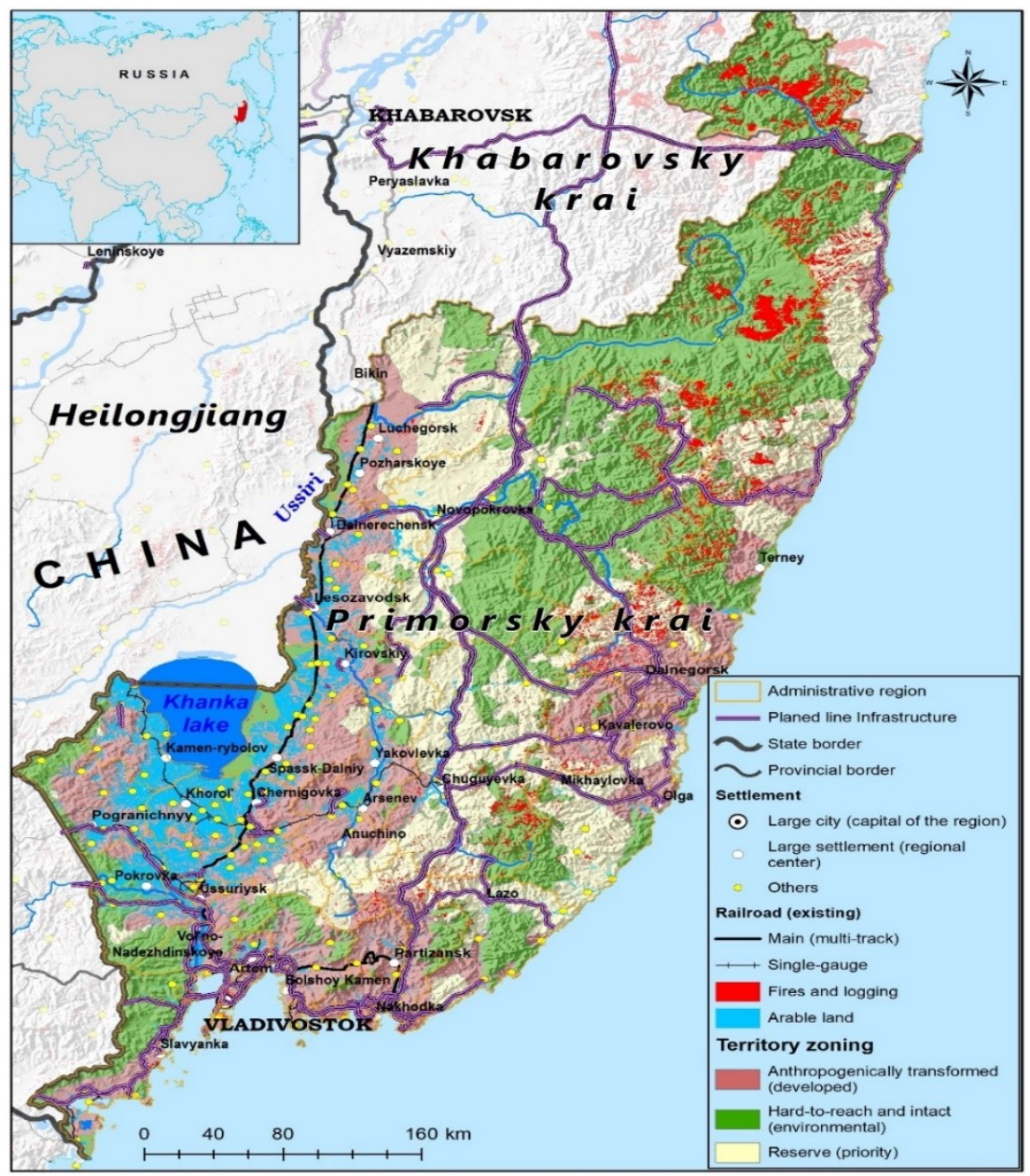

Fig. 1. Socio-economic assessment of settlement, infrastructure, and areas of the high conservation value of the Primorsky region.

Another objective was to identify levels of territorial and demographical development (the current territorial settlement can be shown in detail as a part of the information system). 
Objects of consideration include settlements of all types, the main current and future infrastructure of settlements, transport network including the planned construction, communication lines, routes of pipelines, etc. In order to consider and assess the area of the Primorsky region and take into account the varying climate conditions as well as their spacial development, we identified four groups of municipal entities in accordance with their geographical location: 1 - "Nothern": Krasnoarmeysky, Pozharsky, Terneysky districts; 2 "Central": Dalnerechensky, Kavalerovsky, Kirovsky, Olginsky, Spassky, Chernihiv, Chuguevsky, Yakovlevsky districts; 3 - "Southern": Anuchinsky, Lazovsky, Mikhailovsky, Nadezhdinsky, Partizansky, Khasansky, Shkotovsky districts (including city districts: Artemovsky, Vladivostok, Bolshoy Kamen, Nakhodka, Partizansky, Ussuriysky); 4 "Western": Oktyabrsky, Pogranichny, Khankaysky, Khorolsky districts. The calculation and comparison of wildlife areas with anthropogenically modified areas were made for all districts in the groups (Table 1).

Table 1. Scheme of the presence and protection of wildlife in the Primorsky region.

\begin{tabular}{|c|c|c|c|c|c|c|c|}
\hline \multirow[t]{2}{*}{$\begin{array}{l}\text { Combining } \\
\text { municipal } \\
\text { district into } \\
\text { groups } \\
\text { according to } \\
\text { the geographi } \\
\text { cal location }\end{array}$} & \multicolumn{2}{|c|}{$\begin{array}{l}\text { Exploited area } \\
\text { s, } \\
\text { anthropogenic } \\
\text { ally } \\
\text { transformed } \\
\text { areas }\end{array}$} & \multicolumn{2}{|c|}{$\begin{array}{l}\text { Reserved area, } \\
\text { prioritized for } \\
\text { the development } \\
\text { areas }\end{array}$} & \multicolumn{2}{|c|}{$\begin{array}{l}\text { Hard-to- } \\
\text { reach areas, } \\
\text { low-disturbed } \\
\text { areas, } \\
\text { protected areas }\end{array}$} & \multirow[t]{2}{*}{$\begin{array}{l}\text { Total } \\
\left(\mathrm{Km}^{2}\right)\end{array}$} \\
\hline & $\mathrm{Km}^{2}$ & $\%$ & $\mathrm{Km}^{2}$ & $\%$ & $\mathrm{Km}^{2}$ & $\%$ & \\
\hline 1 & 5819.7 & 8.3 & $\begin{array}{l}18629 . \\
87\end{array}$ & 26.5 & $\begin{array}{l}45800 . \\
8\end{array}$ & 65.2 & 70250.3 \\
\hline 2 & $\begin{array}{l}17690 . \\
7\end{array}$ & 36.6 & $\begin{array}{l}19462 . \\
3\end{array}$ & 40.2 & $\begin{array}{l}11218 . \\
9\end{array}$ & 23.2 & 48371.3 \\
\hline 3 & $\begin{array}{l}19197 . \\
7\end{array}$ & 58.3 & 5631.9 & 17.1 & 8088.2 & 24.6 & 32917.8 \\
\hline 4 & 7649.9 & 76.2 & 195.5 & 1.9 & 2205.8 & 21.9 & 10051.2 \\
\hline
\end{tabular}

When using the administrative and territorial cartographic layer which includes boundaries of administrative, municipal, and national districts and their centers in form of human settlements, the objective was to localize the main administrative clusters, institutional structures, special areas of all types. As for the information systems the measures were taken to develop and implement the integrated GIS (https://amurinfocenter.org/geo/va lues-and-threats/), which combines not only existing anthropogenic changes in nature but also potential investment projects based on strategic environmental assessments of the fareastern region [10]. Let's notice, that the polarized area of the Primorsky region is distinctly different when appealing to the spatial data on anthropogenic fracturing in the form of the built-up areas and areas of the active use of natural resources. In order to identify the areas of wildlife that have official protection status, the spatial analysis was conducted covering the most valuable areas in terms of environmental protection (State nature reserves including biosphere reserves, national parks, reserves of federal importance, the UNESCO world natural heritage sites, wetlands from the RAMSAR international list, key bird areas in Russia. GIS technologies allowed integrating socio-economic and investment data with the most important in a practical sense biological and ecological data on the biodiversity of the Primorsky region (Fig. 2). 


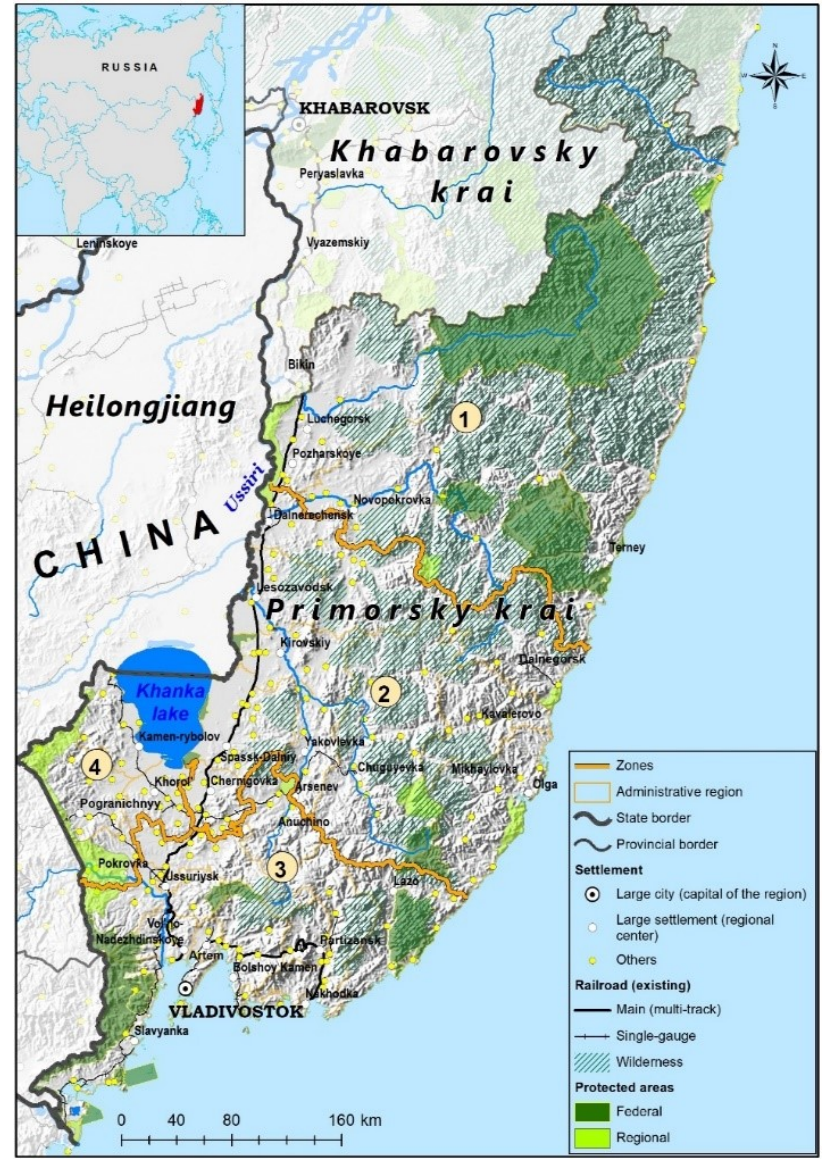

Fig. 2. Environmental zoning and wildlife conservation areas of the Primorsky region.

We note that central parts of the Primorsky region are to a large extent characterized by the possibility of choosing among different priorities of investment development, it may be the optimization of territorial protection (reserved areas consist $23.2 \%$ of the total area) whereas the percentages of the reserved areas and anthropogenically modified landscapes are very high (40.2\% and $36.6 \%$ correspondingly). South and west parts of the Primorsky region are more densely populated and used for productive activities $(58.3 \%$ and $76.1 \%$ correspondingly). We can make a definitive conclusion that the greater importance in frames of conservation of large forest ecosystems is given to the first (the Nothern) nature protection area because it has the lowest percentage of anthropogenically modified areas and there are large protected areas in that region such as Sikhote-Alin nature reserve, Udegeyskaya Legenda national park, and Bikin national park. The largest massifs of undisturbed and undeveloped natural areas are located at that part of the Primorsky region as well.

We are convinced that global changes in spatio-temporal, socio-economic, and environmental characteristics require using efficient methodological instruments of obtaining the operational information including in the visualized form. It explains the demand for geoinformation technologies that allow us to rapidly systematize, visualize, and model the huge arrays of data finding innovative and extraordinary solutions to achieve efficient optimacy in reconciling the conflicting objectives. 


\section{Conclusions}

On the basis of the experience gained from the research, we can conclude that there is a need for a clear geo-ecological focus on solving problems of optimization of natural and anthropological landscapes. Special attention should be paid to the development of rational methods of environmental management and protection, using natural resources in environmentally acceptable ways, and the development of the green economy [11-12]. On the basis of the calculations made, we identified the «no go zone», i.e. areas of exceptional value in terms of the environmental policy of the Primorsky region requiring maximum environmental protection from unsustainable use. Although most of the northern and central areas of the Primorsky region are rented by logging companies of various forms of ownership, these areas belong to forest regions of the habitats of the Amur tiger (Red Book species). Illegal logging, forest fires, poaching in those regions should be highlighted as the factor of negative impact on wildlife. At the same time, ecosystems of the southern regions of the Primorsky region require special environmental attention due to already existing and planned large investment projects. Each of these projects should be carefully and repeatedly considered not only by business and government but also by the environmental community and academic scientific organizations. For such purposes, there are experts and specialists, positive experience of collaboration gained for many years, informational support of high quality - that's what all interested parties should maintain and develop doing the mission of conservation of the wildlife of the Primorsky region.

\section{References}

1. G. B. Kleiner, M. Rybachuk, Fronteiras, 5, 61 (2016)

2. R. E. Ulanowicz, S. J. Goerner, B. Lietaer, R. Gomez, Ecological Complexity, 6(1), 27 (2009)

3. A. Babonea, Theoretical and Applied Economics, 19(10), 105 (2012)

4. R. Costanza, S. Liu, Asia and the Pacific Policy Studies, 1(1), 160 (2014)

5. A. Steblyanskaya, Z. Wang, Z. Bragina, Finance: Theory and practice, 98(045), 134 (2019)

6. V. N. Bocharnikov, E. G. Egidarev, Bulletin of Volgograd State University, Econ. Env., 3, 163 (2016)

7. V. N. Bocharnikov, E. G. Egidarev, Astrakhan Bulletin for Environmental Education, 2, 11 (2017)

8. V. N. Bocharnikov, E. G. Egidarev, I. V. Lindberg, Bulletin of Far Eastern Branch of Russian Academy of Sciences, 2(216), 69 (2021)

9. V. N. Bocharnikov, The global environmental agenda and Russia, Materials of AllRussian Scientific Online Conf. with international participation, 106 (2020)

10. V. N. Bocharnikov, E. G. Egidarev, Environmental transformation and sustainable development in the Asian region, Materials of International Scientific Conf. Irkutsk, 6 (2020)

11. N. N. Barchan, A. N. Suetin, Analysis of the sources of Fundamental research, 11, 228 (2013)

12. B. N. Porfiriev, Scientific Articles: Institute of Economic Forecasting Russian Academy of Sciences, 10 (2012) 